\title{
The Significance of Differences in Melanocortin 3 Levels and their Relationship with Pulmonary Tuberculosis and Body Mass Index
}

\author{
Andi Tenriola ${ }^{1}$ D, Najdah Hidayah ${ }^{1}$ (D), Subair Subair ${ }^{1}$, Muhammad Nasrum Massi ${ }^{2 *}$ (D), Irda Handayani ${ }^{1}$, Rosdiana Natzir $^{3}$ D \\ Irawaty Djaharuddin ${ }^{4}$ iD, Handayani Halik ${ }^{1}$ (D) \\ ${ }^{1}$ Postgraduate Program, Faculty of Medicine, Universitas Hasanuddin, Makassar, Indonesia; ${ }^{2}$ Department of Microbiology, \\ Faculty of Medicine, Universitas Hasanuddin, Makassar, Indonesia; ${ }^{3}$ Department of Biochemistry, Faculty of Medicine, \\ Universitas Hasanuddin, Makassar, Indonesia; ${ }^{4}$ Department of Pulmonology and Respiratory, Faculty of Medicine, Universitas \\ Hasanuddin, Makassar, Indonesia
}

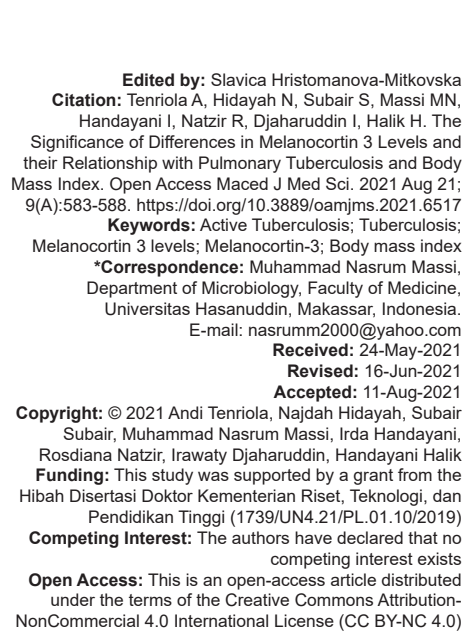

\section{Introduction}

In $2019,87 \%$ of new tuberculosis (TB) cases occurred in 30 countries with a high burden of TB [1]. Eight countries account for two-thirds of new TB cases, including Indonesia, which is second only to India [2]. The WHO estimates that approximately 10 million people have TB worldwide from various age groups and sexes, with an estimated 5.6 million men, 3.2 million women, and 1.2 million children [3].

Pulmonary TB remains the leading cause of morbidity and mortality worldwide, with about one-third of the world's population infected. Between $10 \%$ and $20 \%$ of those infected will develop active TB, posing a serious health threat [4]. TB is caused by Mycobacterium tuberculosis which attacks the lungs and is transmitted through exposure to air [5]. Currently, TB transmission occurs so fast due to contact with sufferers, and the most infected is the person closest to the patient [6]. TB cases from household contacts are usually higher than in the general population [7].

Several previous studies tried to find out the susceptibility of melanocortin 3 Receptors (MC3R) levels to TB, one of which was Lindsey et al., who confirmed the relationship between MC3R and TB exposure in the South African population at SNP rs6127698 $(p=0.0004)$ [8]. TB at different rates among certain races, ethnicities, and families indicates an other genetic predisposition [9]. Apart from TB, MC3R is also associated with body mass index because the melanocortin system plays an essential role in energy homeostasis [10]. Bodyweight shows remarkable stability over time, even in obese people [11]. This suggests a mechanism for sensing energy balance and preventing excess weight gain through control of appetite and energy expenditure and/or nutrient sharing [12]. A popular concept for "energy homeostasis" has developed in which body weight is maintained by neural circuits originating in the hypothalamus 
that link appetite and autonomic and neuroendocrine metabolic control with metabolic status signals [13]. Recent studies examining the genetic underpinnings of obesity have shown that MC3R play a role in body composition and nutrient partitioning by playing a central role in eating behavior [14]. MC3R is essential for expressing anticipatory responses and metabolic homeostasis when food intake occurs outside of the normal photoperiod-driven voluntary rhythm [10].

In this study, we identified differences in MC3R levels on the TB, age, sex, and Body mass index (BMI) variables to see the significance and the relationship between them to serve as a reference in differentiating disease states and determining biomarkers for early diagnosis of health conditions future disease risk.

\section{Subjects and Methods}

A total of 132 vulnerable respondents aged 17-70 years were invited to this study to take blood samples. We determined inclusion criteria for three groups; 53 new cases of active TB patients, positive smear results, chest X-rays, showed infiltrate. Fourty-nine household contacts with active TB patients did not show symptoms of active TB, and were willing to do the IGRA test. Thirty healthy controls who showed no symptoms of active TB, had no chronic disease, and all were selected from the three body mass index groups. The limitation of the exclusion criteria for this study was patients with smear-positive pulmonary TB who had previously received opioid agonist therapy therapy. TB patients were recruited from Puskesmas Makassar, South Sulawesi, Indonesia, and household contacts were selected from the closest family of TB patients. Samples were taken from various places in Makassar, Indonesia.

Blood samples 6-7 cc were collected from each TB patient, household contact, and healthy controls for the IGRA examination at the Laboratory (Hasanuddin University Medical Research Center) Makassar, Indonesia. The blood samples obtained were centrifuged at $4400 \mathrm{rpm}$ for $10 \mathrm{~min}$ at $250^{\circ} \mathrm{C}$ to separate the plasma samples. Plasma samples were stored at $-200^{\circ} \mathrm{C}$ before the ELISA assay to determine the serum MC3R level. Furthermore, ELISA was carried out using Human Melanocortin Receptor 3 ELISA KIT Cat. No E4775Hu [15].

This study was approved by the Research Ethics Commission of the Hasanuddin University Faculty of Medicine, Makassar, South Sulawesi, Indonesia (No. 517/H4.8.4.5.31/PP36-KOMETIK/2018 on July 27,2018 ), and all research subjects were given written consent.

\section{Statistic analysis}

All experimental data were analyzed using SPSS 21, where a $p<0.05$ was considered statistically significant. ELISA results were analyzed to assess differences in MC3R levels in each group. Statistical analysis was performed using the ANOVA test for different values between groups. Then, the Post hoc test was carried out to see the significance of the difference between the two variables and the Pearson correlation test to see the correlation between variables.

\section{Results}

A total of 132 people were divided into three groups, namely, active TB 53 people (40.2\%), household contacts 49 people $(37.1 \%)$, and healthy controls 30 people $(22.7 \%)$ as seen in [Table 1]. The 132 people were randomly selected based on gender, age, and body mass index status and met the sample criteria.

Table 1: Sample characteristics based on gender, age, and body mass index

\begin{tabular}{|c|c|c|c|c|}
\hline Variable & TB active & Household contact & Healthy control & p-value \\
\hline \multicolumn{5}{|l|}{ Gender } \\
\hline Male & 31 & 17 & 10 & \multirow[t]{2}{*}{$0.22^{\dagger}$} \\
\hline Female & 22 & 32 & 20 & \\
\hline \multicolumn{5}{|l|}{ Age } \\
\hline $17-29$ years & 11 & 15 & 8 & \multirow[t]{3}{*}{$0.09^{\dagger}$} \\
\hline $30-49$ years & 25 & 25 & 22 & \\
\hline $50-70$ years & 8 & 22 & 0 & \\
\hline \multicolumn{5}{|l|}{ BMI } \\
\hline Under weight & 24 & 10 & 10 & \multirow[t]{3}{*}{$0.073^{\dagger}$} \\
\hline Normal & 17 & 17 & 10 & \\
\hline Overweight & 12 & 22 & 10 & \\
\hline
\end{tabular}

The highest average MC3R level was found in the active TB group at 1,259.55 and the lowest was in the healthy control at 503.26 with $p=0.028$, which means that there was a significant difference in MC3R levels in the three groups as we can see in [Figure 1].

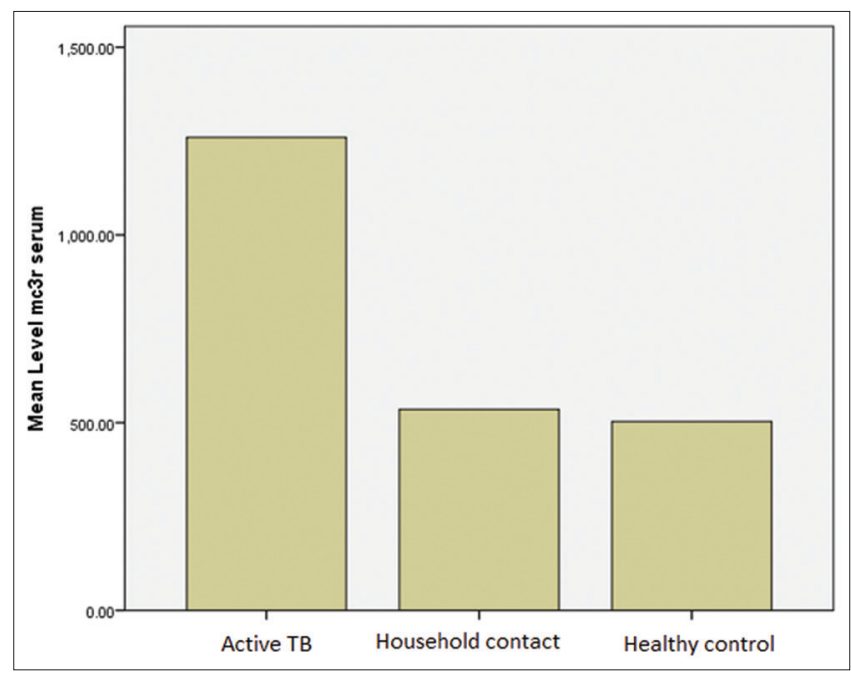

Figure 1: Differences in the mean value of melanocortin 3 levels in active tuberculosis, household contacts, and healthy controls 
Based on Table 2, the differences in MC3R levels between the active TB group and household contacts were significantly different with a value of $p=0.019(p<$ 0.05). The active TB group and the healthy control group were also significantly different. different $p=0.033(p<$ $0.05)$, while household contacts and healthy controls did not show a significant difference with $p=0.929(p>0.05)$.

Table 2: Significance of MC3R level differences between variables based on health status

\begin{tabular}{lll}
\hline Group & $p$-value & Conclusion \\
\hline Active TB - Home contact & $0.019^{*}$ & Very different \\
Active TB - Healthy control & $0.033^{*}$ & Very different \\
Home contact - Healthy control & $0.929^{*}$ & There is no significant difference \\
\hline Post hoc test. MC3R: Melanocortin 3 receptors, TB: Tuberculosis.
\end{tabular}

Next, in Figure 2, we analyzed the differences in the mean levels of MC3R in the active TB group, household contacts, and healthy controls, wherein these data we identified differences based on sex. In the three groups above, it was clear that the highest MC3R levels were male, although not significantly with a $p=0.551$.

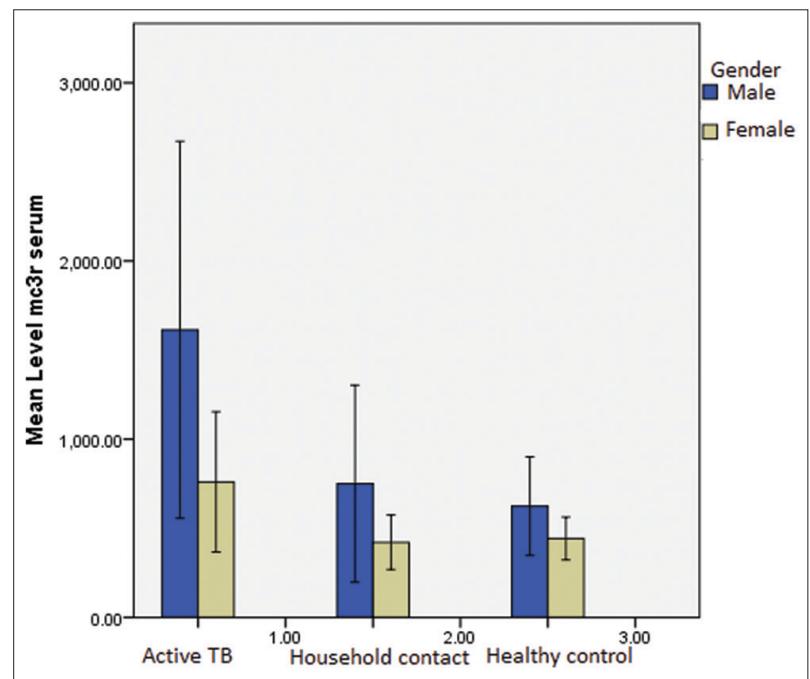

Figure 2: Differences in the mean value of Melanocortin 3 levels in active tuberculosis, household contacts, and healthy controls based on the sex of the sample

Based on Figure 3, in the three sample age groups, the highest median value of MC3R levels is

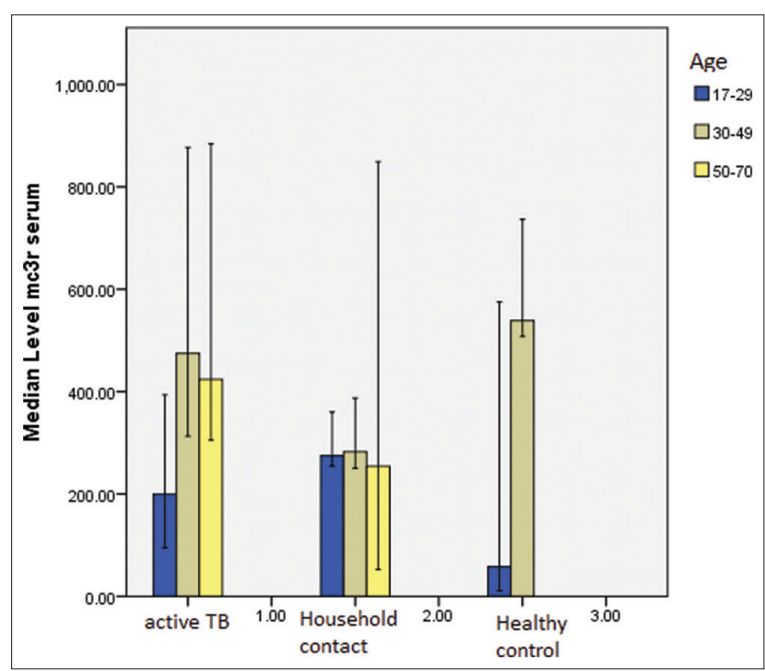

Figure 3: The difference in median Melanocortin 3 levels in active tuberculosis, household contacts, and healthy controls by age group at the susceptible age of $30-49$ years with $p=0.028$ which means significant.

Based on the chart in Figure 4, it is known that people with excess BMI had a higher median MC3R level in all three groups (active TB, household contacts, and healthy controls, and the highest MC3R levels with excess BMI were in the active TB group with a $p=0.006$ which was means significant.

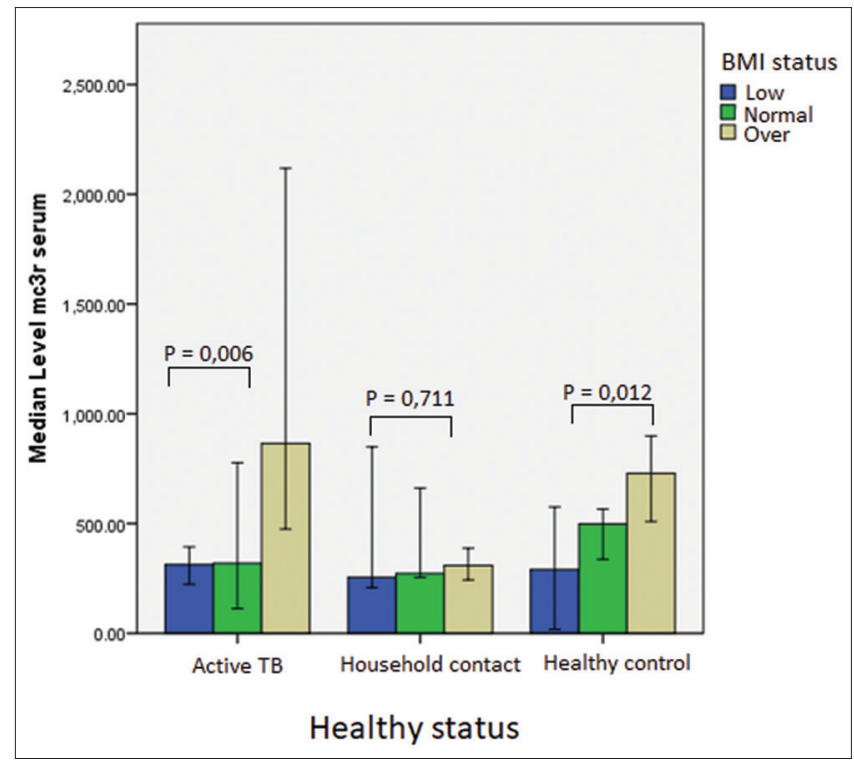

Figure 4: Comparison of median melanocortin 3 levels serum in the active tuberculosis group, household contacts, and healthy controls based on body mass index status

\section{Discussion}

Based in Table 3, there was a significant difference in MC3R levels in the three groups with different health status with a $p=0.028$. The active TB group had the highest rates, and the healthy control group had the lowest rates. High values of MC3R levels against active TB are associated with the physiological role of MC3R as a regulator of energy metabolism and the immune system [16]. This is also supported by the results of the correlation analysis between MC3R levels

Table 3: The correlation between MC3R levels with several variables used Pearson's correlation

\begin{tabular}{|c|c|c|}
\hline Variable & $\mathrm{r}$ & $\mathrm{p}$-value \\
\hline \multicolumn{3}{|l|}{ Healthy status } \\
\hline Active TB & $0.232^{* *}$ & 0.008 \\
\hline Household contact & -0.140 & 0.110 \\
\hline Heathy control & -0.110 & 0.210 \\
\hline \multicolumn{3}{|l|}{ Gender } \\
\hline Male & 0.211 * & 0.015 \\
\hline Female & $-0.211^{*}$ & 0.015 \\
\hline \multicolumn{3}{|l|}{ Age } \\
\hline $17-29$ years & $-0.201^{*}$ & 0.021 \\
\hline $30-49$ years & $0.171^{*}$ & 0.050 \\
\hline $50-70$ years & 0.007 & 0.939 \\
\hline \multicolumn{3}{|l|}{ BMI } \\
\hline Under weight & 0.036 & 0.685 \\
\hline Normal & 0.019 & 0824 \\
\hline Over weight & -0.055 & 0.530 \\
\hline
\end{tabular}


and the active TB group, it was found that there was a relationship between $M C 3 R$ and active TB with a $p$ $=0.008$. MC3R is an essential regulator for regulating human physiological responses when sick or healthy and plays a role in immune activity [17]. MC3R is closely related to $\alpha-\mathrm{MSH}$, a polypeptide form of $\mathrm{MSH}$ consisting of 13 amino acids [18]. In the pathophysiology of a disease, $\alpha-\mathrm{MSH}$ suppresses inflammation and promotes the activation of inflammatory activity and immune regulation through MC1R, MC3R, and MC5R, whereas in macrophages, $\alpha-\mathrm{MSH}$ mediates alternative activation where macrophages suppress inflammation via MC1R and MC3R [19]. Macrophages have the ability to destroy invading micro bacteria, including Mtb [20]. Although pathogens have an extraordinary capacity to survive in a hostile macrophage environment, primary infection does not cause active TB disease in most people, even those who have been latently infected [21]. The majority of individuals remain infected latently, where the bacteria are controlled by the host's immune response [22]. In the pathogenesis process of TB, the resistance between Mycobacterium and macrophages will produce two possibilities; if macrophage cells are strong, then it will destroy Mtb, but if macrophages are weak, then Mtb will continue to replicate in macrophage cells or a specific immune system will continue to work to attack Mtb, macrophages will surround Mtb and form multinucleated cells [23]. This triggers an increase in melanocortin levels including MC3R and plays an essential role in promoting anti-inflammatory activity and immune regulation against Mtb [19]. In a previous study, in yellow mice with Goutyritis, it was found that MC3R mediated the anti-inflammatory effect of $\gamma-\mathrm{MSH}$ which dependently reduces the release of interleukin-1 and chemokines. The same group also reported the melanocortin MC 3 receptor-dependent anti-inflammatory efficacy of D-Trp $8-\gamma$-MSH in models of vascular inflammation and pneumonia [24], [25].

In the sex group, although of the three health status groups, men had the highest levels, the results were not so significant with a value of $p=0.551$, so we could not dig up much from these results, but the results differed after the correlation test was carried out, It turns out that both sex groups have a correlation with MC3R levels, where men have a positive correlation with a value of $p=0.015$ and women have a negative correlation with a value of $p=0.015$ which indicates that both are significant. There are not many specific explanations about Melanocortin 3 and gender that we can get, this is also what this study lacks. However, several previous studies have linked MC3R with gender behavior which is believed to be associated with MC3R expression in ventral tegmental area (VTA) [26]. Anna I, previously published a study entitled VTA MC3R neurons control feeding in an activity and sex-dependent manner in mice, and the result was that VTA MC3R neurons acutely control feeding in sex and activity-dependent way, but there was no difference in numbers. total neurons in VTA MC3R, percentage of VTA MC3R neurons in both sexes [27]. The study above does not explicitly explain the relationship between sex and MC3R, but this is a reference for conducting further research to determine the specific relationship between MC3R and sex.

Age and body mass index were associated with MC3R function in maintaining energy homeostasis. The 30-49 year age group had a significant increase in the median value in the three groups (active TB, household contacts, and healthy) with a value of $p=0.028$, and was followed by the results of a correlation analysis that explained a significant correlation between MC3R and the 17-29 year age group. although the correlation was negative $(p=0.021)$, and also in the 30-49 year age group with a positive correlation $(p=0.050)$. The two groups above are productive and prime-age categories, which physiologically require large energy intake and are susceptible to metabolic function [28]. At a productive age, the functions of various organs of the body are very optimal, the bodies of people of productive age can make repairs and maintain their optimal function, likewise with homeostasis and autonomic function involving MC3R [29]. Indeed, no studies discuss the relationship between age and MC3R but based on the theory of aging, we linkage and MC3R to be very closely related to the function of $M C 3 R$ in maintaining homeostasis and body autonomic function according to age levels [14], [29].

Finally, we looked for the association of MC3R with body mass index, which is not a new discussion anymore, but previous researchers have frequently discussed previous researchers. This study found that the mean MC3R value increased significantly in the overweight group in three groups (with a significant increase in the active TB group $p=0.006$, and in the healthy control group $p=0.012$ ) it did not have a significant correlation. On obesity, its genetic pathogenesis is complex, with over a hundred candidate genes or regions involved, including MC4R and MC3R involved [30]. MC3R can regulate metabolism not only through the center, but through peripheral actions of the periphery, so its impact on energy homeostasis is not direct [10]. The effects of MC3R are regulated by the binding of endogenous melanocortin ligands, the release, and sequence of which is signaled [14]. In the arcuate nucleus, MC3R functions as an inhibitory autoreceptor for POMC neurons, where the function of this POMC is to release $\alpha-M S H$ to reduce appetite [31]. MC3R appears to not only regulate the activation status of POMC neurons but also regulate body weight in the central nervous system and other peripheral sites [32]. $M C 3 R$ activation is orexigenic, and MC3R in the limbic system is important to motivate feeding after energy inhibition, so it can be concluded that MC3R activation also regulates the increase in one's appetite [33]. Buttler and Roger Cone's study has reported that mice with MC3R inactivation have greater anorexia and loss of lean tissue in response to lipopolysaccharide injection, as well as an eating disorder response to fasting, although 
the clear mechanism by which MC3R alters metabolism leads to obesity has not been fully identified [34].

Previous studies discussed more the MC3R and MC4R mutations in obesity. Based on location and biology, MC3R is a candidate gene that is included in the mutation candidate for obesity. In contrast, based on its structure, MC3R has a role similar to that of MC4R in blocking $\alpha-\mathrm{MSH}$ through competitive antagonism [35]. In a cohort study in Belgium, $1.6 \%$ of obese people also had MC3R mutases compared with $1.7 \%$ in non-obese subjects [36]. Furthermore, another study of 839 obese subjects and 967 control subjects in Italy revealed that the frequency of rare MC3R mutations was $1.55 \%$ in the obese group compared to $0.83 \%$ in the non-obese group [37]. In another review, written by Andrew et al., entitled "Polymorphism and mutations in the Melanocortin-3 receptor and their relation to human obesity" concluded that the association between obesity and MC3R is also influenced by haplotype variants. Multiple MC3R deletions and mutations lead to obesity phenotypes [14], [38].

\section{Conclusion}

High levels of MC3R were found in active TB patients and were closely related to immune activity against Mtb, and this also explains the reason healthy respondents had stable MC3R levels because there was no significant immune activity. In respondents with excess body mass index, the mean MC3R levels increased significantly, which was associated with the function of MC3R as an autoreceptor inhibiting POMC neurons and regulating appetite.

\section{References}

1. Kim J, Keshavjee S, Atun R. Health systems performance in managing tuberculosis: Analysis of tuberculosis care cascades among high-burden and non-highburden countries. J Glob Health. 2019;9(1):010423. https://doi.org/10.7189/ jogh.09.010423

2. Chakaya J, Khan M, Ntoumi F, Aklillu E, Fatima R, Mwaba P, et al. Global tuberculosis report 2020 reflections on the global TB burden, treatment and prevention efforts. Int J Infect Dis. 2021;2021:107. https://doi.org/10.1016/j.ijid.2021.02.107

3. Global Tuberculosis Report; 2018. Availale from: http://www. apps.who.int/bookorders. [Last accessed on 2021 Apr 23].

4. Jilani TN, Avula A, Gondal AZ, Siddiqui AH. Active Tuberculosis. Treasure Island, FL: StatPearls Publishing; 2021.

5. Turner RD, Chiu C, Churchyard GJ, Esmail H, Lewinsohn DM, Gandhi NR, et al. Tuberculosis infectiousness and host susceptibility. J Infect Dis. 2017;216(Suppl 6):S636-43. https:// doi.org/10.1093/infdis/jix361

PMid:29112746

6. Eom JS, Kim I, Kim WY, Jo EJ, Mok J, Kim MH, et al. Household tuberculosis contact investigation in a tuberculosis-prevalent country. Medicine (United States). 2018;97(3):e9681. https:// doi.org/10.1097/MD.0000000000009681

PMid:29505017

7. Adane A, Damena M, Weldegebreal F, Mohammed $H$ Prevalence and associated factors of tuberculosis among adult household contacts of smear positive pulmonary tuberculosis patients treated in public health facilities of Haramaya district, Oromia Region, Eastern Ethiopia. Tuberc Res Treatment. 2020;2020:1-7. https://doi.org/10.1155/2020/6738532

8. Adams LA, Möller M, Nebel A, Schreiber S, Van Der Merwe L, Van Helden PD, et al. Polymorphisms in MC3R promoter and CTSZ $3^{\prime}$ UTR are associated with tuberculosis susceptibility. Eur J Hum Genet. 2011;19(6):676-81. https://doi.org/10.1038/ ejhg.2011.1

PMid:21368909

9. Hayward S, Harding RM, McShane H, Tanner R. Factors influencing the higher incidence of tuberculosis among migrants and ethnic minorities in the. F1000Res. 2018;7:461. https://doi. org/10.12688/f1000research.14476.2

PMid:30210785

10. Begriche K, Girardet C, McDonald P, Butler AA Melanocortin-3 receptors and metabolic homeostasis. Prog Mol Biol Transl Sci. 2013;114:109-46. https://doi.org/10.1016/ B978-0-12-386933-3.00004-2 PMid:23317784

11. Hruby A, Hu FB. The epidemiology of obesity: A big picture Pharmacoeconomics. 2015;33(7):673-89. https://doi. org/10.1007/s40273-014-0243-x

PMid:25471927

12. Chapelot D, Charlot K. Physiology of energy homeostasis: Models, actors, challenges and the glucoadipostatic loop. Metabolism. 2019;92:11-25. https://doi.org/10.1016/j. metabol.2018.11.012

PMid:30500561

13. Liu T, Xu Y, Yi CX, Tong Q, Cai D. The hypothalamus for wholebody physiology: From metabolism to aging. Protein Cell. 2021;2021:1-28. https://doi.org/10.1007/s13238-021-00834-x PMid:33826123

14. Demidowich AP, Jun JY, Yanovski JA. Polymorphisms and mutations in the melanocortin-3 receptor and their relation to human obesity. Biochim Biophys Acta Mol Basis Dis. $\quad 2017 ; 1863(10): 2468-76$. https://doi.org/10.1016/j. bbadis.2017.03.018

PMid:28363697

15. Laboratorium teknologi bioassay. Kit Elisa Serum Amiloid A Manusia; 2017. Available from: http://www.bt-laboratory.com/ wp-content/uploads/2019/07/Human-Serum-amyloid-ASAAELISA-Kit-40.doc. [Last accessed in 2021 April 20].

16. Clemson CM, Yost J, Taylor AW. The role of Alpha-MSH as a modulator of ocular immunobiology exemplifies mechanistic differences between melanocortins and steroids. Ocular Immunol Inflamm. 2017;25(2):179-89. https://doi.org/10.3109/0 9273948.2015.1092560

PMid26807874

17. Trevaskis JL, Gawronska-Kozak B, Sutton GM, McNeil M, Stephens JM, Smith SR, et al. Role of adiponectin and inflammation in insulin resistance of $\mathrm{Mc} 3 \mathrm{r}$ and $\mathrm{Mc} 4 \mathrm{r}$ knockout mice. Obesity. 2007;15(11):2664-72. https://doi.org/10.1038/ oby. 2007.318 PMid18070757

18. Cai M, Hruby VJ. The melanocortin receptor system: A target for multiple degenerative diseases. Curr Protein Pept Sci. 2016;17(5):488-96. https://doi.org/10.2174/1389203717666160 226145330 


\section{PMid26916163}

19. Wang W, Guo DY, Lin YJ, Tao YX. Melanocortin regulation of inflammation. Front Endocrinol. 2019;10:683. https://doi. org/10.3389/fendo.2019.00683

\section{PMid31649620}

20. Upadhyay S, Mittal E, Philips JA. Tuberculosis and the art of macrophage manipulation. Pathog Dis. 2018;76(4):37. https:// doi.org/10.1093/femspd/fty037

PMid29762680

21. Hunter RL. The pathogenesis of tuberculosis: The early infiltrate of post-primary (adult pulmonary) tuberculosis: A distinct disease entity. Front Immunol. 2018;9:2108. https://doi.org/10.3389/ fimmu.2018.02108.

22. Khan A, Singh VK, Hunter RL, Jagannath C. Macrophage heterogeneity and plasticity in tuberculosis. J Leukocyte Biol. 2019;106(2):275-82. https://doi.org/10.1002/JLB. MR0318-095RR

\section{PMid30938876}

23. Zhai W, Wu F, Zhang Y, Fu Y, Liu Z. The immune escape mechanisms of Mycobacterium tuberculosis. Int J Mol Sci. 2019;20(2):340. https://doi.org/10.3390/ijms20020340

24. Getting SJ, Lam CW, Chen AS, Grieco P, Perretti M. Melanocortin 3 receptors control crystal-induced inflammation. FASEB J. 2006;20(13):2234-41. https://doi.org/10.1096/fj.06-6339com PMid17077300

25. Patel HB, Leoni G, Melendez TM, Sampaio AL, Perretti M. Melanocortin control of cell trafficking in vascular inflammation. Adv Exp Med Biol. 2010;681:88-106. https://doi. org/10.1007/978-1-4419-6354-3_7 PMid21222262

26. Lippert RN, Ellacott KL, Cone RD. Gender-specific roles for the melanocortin-3 receptor in the regulation of the mesolimbic dopamine system in mice. Endocrinology. 2014;155(5):1718-27. https://doi.org/10.1210/en.2013-2049

PMid24605830

27. Dunigan Al, Olson DP, Roseberry AG. VTA MC3R neurons control feeding in an activity and sex-dependent manner in mice Title: VTA MC3R neurons control feeding by sex. BioRxiv. 2021;2021:434586. https://doi.org/10.1101/2021.03.09.434586

28. Amarya S, Singh K, Sabharwal M. Changes during aging and their association with malnutrition. J Clin Gerontol Geriatr. 2015;6(3):78-84. https://doi.org/10.1016/j.jcgg.2015.05.003

29. LeBouef T, Whited L. Physiology, Autonomic Nervous System. Treasure Island, FL: StatPearls Publishing; 2019.
30. Li WD, Joo EJ, Furlong EB, Galvin M, Abel K, Bell CJ, et al. Melanocortin 3 receptor (MC3R) gene variants in extremely obese women. Int J Obes. 2000;24(2):206-10. https://doi. org/10.1038/sj.ijo.0801114

PMid10702772

31. Date Y, Shimbara T, Koda S, Toshinai K, Ida T, Murakami N, et al. Peripheral ghrelin transmits orexigenic signals through the noradrenergic pathway from the hindbrain to the hypothalamus. Cell Metab. 2006;4(4):323-31. https://doi.org/10.1016/j. cmet.2006.09.004

PMid17011505

32. Girardet C, Marks DL, Butler AA. Melanocortin-3 receptors expressed on agouti-related peptide neurons inhibit feeding behavior in female mice. Obesity. 2018;26(12):1849-55. https:// doi.org/10.1002/oby.22306

PMid30426710

33. Mavrikaki M, Girardet C, Kern A, Brantley AF, Miller CA, Macarthur $\mathrm{H}$, et al. Melanocortin-3 receptors in the limbic system mediate feeding-related motivational responses during weight loss. Mol Metab. 2016;5(7):566-79. https://doi.org/10.1016/j. molmet.2016.05.002

PMid27408780

34. Butler AA, Cone RD. The melanocortin receptors: Lessons from knockout models. Neuropeptides. 2002;36(2-3):77-84. https:// doi.org/10.1054/npep.2002.0890

PMid12359499

35. Girardet C, Butler AA. Neural melanocortin receptors in obesity and related metabolic disorders. Biochim Biophys Acta Mol Basis Dis. 2014;1842(3):482-94. https://doi.org/10.1016/j. bbadis.2013.05.004

PMid23680515

36. Zegers D, Beckers S, Hendrickx R, Van Camp JK, Van Hoorenbeeck K, Desager KN, et al. Prevalence of rare MC3R variants in obese cases and lean controls. Endocrine. 2013;44(2):386-90. https://doi.org/10.1007/s12020-012-9862-1 PMid23264184

37. Yang Z. Human Melanocortin-3 Receptor: Structure-function Relationship of DPLIY Motif and Helix 8 and Biased Signaling; 2016.

38. Mencarelli M, Dubern B, Alili R, Maestrini S, Benajiba L, Tagliaferri $M$, et al. Rare melanocortin-3 receptor mutations with in vitro functional consequences are associated with human obesity. Hum Mol Genet. 2011;20(2):392-9. https://doi. org $/ 10.1093 / \mathrm{hmg} / \mathrm{ddq} 472$

PMid:21047972 